\title{
Risk of venous thromboembolism with oral contraceptives
}

\section{Susan Solymoss MD}

See related research article by Gronich and colleagues at www.cmaj.ca/lookup/doi/10.1503/cmaj.110463

Competing interests:

None declared.

This article was solicited and has not been peer reviewed.

Correspondence to: Dr. Susan Solymoss, susan.solymoss@mcgill.ca

CMAJ 2011. DOI:10.1503 /cmaj.111614
$\mathrm{T}$ he lifetime incidence of venous thromboembolism for both men and women is estimated at 1 per $1000 .^{1}$ Increasing our understanding of the precipitating risk factors, as well as optimizing the prevention of this condition in high-risk populations, could help to reduce the burden of venous thromboembolism. A retrospective cohort study by Gronich and colleagues $^{2}$ challenges us to weigh the thrombotic risk of various oral contraceptives.

Older age, admission to hospital, surgery, cancer and other comorbidities dramatically increase the rate of venous thromboembolism. Conversely, effective thromboprophylaxis is known to substantially reduce the incidence. The difficulty of ensuring good compliance with thromboprophylaxis remains a major barrier to reducing the adverse outcomes associated with venous thromboembolism. ${ }^{3}$

The absolute rate of venous thromboembolism in young women is low, but the use of combined oral contraceptives increases this rate three- to five-fold, with an even higher rate in the presence of associated risk factors such as thrombophilia. ${ }^{4}$ Gronich and colleagues ${ }^{2}$ focus our attention on women 12 to 50 years of age taking hormonal contraceptives and attempt to quantify the relative difference in risk of venous thromboembolism attributable to the type of oral contraceptive prescribed.

The reported incidence of venous thromboembolism in users of oral contraceptives is about 0.06 per 100 pill-years, ${ }^{5}$ significantly lower than the rate of 0.2 per 100 years at risk during pregnancy and the postpartum period. ${ }^{6}$ The high contraceptive efficacy of oral contraceptives, despite their thrombotic risk, should be weighed against

\section{- Ker POINTS}

- The absolute risk of thrombotic events in young women is low, but increases with pregnancy and the use of oral contraceptives.

- All oral contraceptives are associated with some risk of venous thromboembolism, a risk that should be taken into consideration when these drugs are prescribed.

- Recent studies provide evidence that drospirenone-containing oral contraceptives may be associated with a relative increase in venous thrombotic risk, compared with other oral contraceptives. the risks associated with less effective contraception methods, including the potential thrombotic consequences of an unwanted pregnancy.

The aim of numerous previous studies has been to evaluate the differential thrombotic risk of third-generation (containing desogestrel, gestodene or norgestimate) and secondgeneration (containing norgestrel or levonorgestrel) oral contraceptives. Although not completely consistent, the overall findings have substantiated a relatively lesser thrombotic risk with the use of second-generation contraceptives, albeit with heterogeneity among the studies.

Drospirenone-containing oral contraceptives, which have become available more recently, have a mineralocorticoid-derived progestational component. The study by Gronich and colleagues $^{2}$ adds further evidence of a higher relative risk of venous thromboembolism among women taking this type of oral contraceptive, relative to the alternatives of either third- or second-generation oral contraceptives. Although earlier publications did not detect any such relative difference in thrombotic risk, ${ }^{8}$ carefully designed evaluations performed more recently have found evidence of such a risk. ${ }^{9}$ The industry-funded phase IV European postmarketing surveillance study ${ }^{8}$ collected data by mailed questionnaires from women for whom an oral contraceptive had been newly prescribed. In that study, all subgroups of pill users (categorized by additional risk factors or by drug prescribed) had a similar incidence of venous thromboembolism, which, according to the study design, excluded the possibility of a twofold higher incidence of venous thromboembolism in drospirenone users and provided evidence of non-inferiority. ${ }^{8}$ Subsequently, a large case-control study that evaluated a substantially larger database (in terms of women-years of pill use) ${ }^{9}$ more convincingly demonstrated a difference in thrombotic risk. The authors of that study compared incidence rates of idiopathic, nonfatal venous thromboembolism between drospirenone users and levonorgestrel users, a comparison that emphasized the subset of events most likely influenced by the type of oral contraceptive used. The increased

All editorial matter in CMAJ represents the opinions of the authors and not necessarily those of the Canadian Medical Association. 
risk ratio with drospirenone use remained significant across all age groups, as well as with new and "switch" users. Publication of that study prompted a safety announcement from the US Food and Drug Administration, which is now reviewing additional data from a large study that it commissioned on this subject..$^{10}$ Any forthcoming conclusions from regulatory authorities will likely influence pending litigation and may also influence our future prescribing habits.

Therapeutic decisions for our patients should always be individualized and, in the case of contraception, should always reflect a careful evaluation of the indications for use of an oral contraceptive, any possible alternatives, the patient's preference, the overall thrombotic risk and the ways in which we may be able to minimize any additional thrombotic effect of hormonal therapy prescribed. From the perspective of reducing venous thromboembolism, carefully analyzed answers as to who should use oral contraceptives, and why and when they should use these drugs, will substantially influence comparative thrombotic risk. For example, young, otherwise well women are unlikely to experience thrombotic complications. However, older women and those with comorbidities associated with thrombotic risk, such as obesity, admission to hospital and cancer, need to be aware of the increased thrombotic risk of taking oral contraceptives.

Any use of combined oral contraceptives is associated with an increased risk of venous thromboembolism, even though the absolute rates of venous thromboembolism for the majority of users are generally low. Therefore, our primary focus should be to carefully consider suitable alternatives to combined oral contraceptives for women otherwise at elevated risk of venous thromboembolism and to completely avoid use of these drugs by women with absolute contraindications.

Studies to date provide evidence of a rela- tively greater increase in risk associated with drospirenone. However, the absolute difference in incidence of venous thromboembolism between different oral contraceptives is small, and no regulatory authority or professional body has formally recommended against using drospirenone. Further data may help to formulate a balanced risk assessment in the near future. $^{10}$

\section{References}

1. White RH. The epidemiology of venous thromboembolism. Circulation 2003;107(23 Suppl):I4-8.

2. Gronich N, Lavi I, Rennert G. Higher risk of venous thrombosis associated with drospirenone-containing oral contraceptives: a population-based cohort study. CMAJ 2011;183:2103.

3. Geerts WH, Bergqvist D, Pineo GF, et al. Prevention of venous thromboembolism: American College of Chest Physicians evidence-based clinical practice guidelines (8th edition). Chest 2008; 133:381S-453S.

4. van Vlijmen EFW, Veeger NJGM, Middeldorp S, et al. Thrombotic risk during oral contraceptive use and pregnancy in women with factor $\mathrm{V}$ Leiden or prothrombin mutation: a rational approach to contraception. Blood 2011;118:2055-61.

5. Lidegaard $\emptyset$, Løkkegaard E, Svendsen AL, et al. Hormonal contraception and risk of venous thromboembolism: national follow-up study. BMJ 2009;339:b2890.

6. Heit JA, Kobbervig CE, James AH, et al. Trends in the incidence of venous thromboembolism during pregnancy or postpartum: a 30-year population-based study. Ann Intern Med 2005; 143:697-706.

7. Hennessy S, Berlin JA, Kinman JL, et al. Risk of venous thromboembolism from oral contraceptives containing gestodene and desogestrel versus levonorgestrel: a meta-analysis and formal sensitivity analysis. Contraception 2001;64:125-33.

8. Dinger JC, Heinemann LAJ, Kühl-Habich D. The safety of a drospirenone-containing oral contraceptive: final results from the European Active Surveillance Study on oral contraceptives based on 142475 women-years of observation. Contraception 2007;75:344-54

9. Jick SS, Hernandez RK. Risk of non-fatal venous thromboembolism in women using oral contraceptives containing drospirenone compared with women using oral contraceptives containing levonorgestrel: case-control study using United States claims data. BMJ 2011;342:d2151.

10. FDA Drug Safety Communication: Safety review of possible increased risk of blood clots with birth control pills containing drospirenone. Silver Spring (MD): US Food and Drug Administration; 2011. Available: www.fda.gov/Drugs/DrugSafety /ucm257164.htm (accessed 2011 Sept. 20).

Affiliation: Susan Solymoss is with St. Mary's Hospital Centre, McGill University Health Centre, Montréal, Que. 